DOI: $10.14451 / 1.169 .102$

\title{
РАЗВИТИЕ НАУЧНЫХ ПРЕДСТАВЛЕНИЙ О КРЕДИТЕ И ПОТРЕБИТЕЛЬСКОМ КРЕДИТОВАНИИ
}

\author{
(C) 2018 Архипова Евгения Михайловна \\ Начальник Финансового управления ООО «Консалтинговая группа «Финиум» \\ 127055, г. Москва, ул. Новослободская, д. 14/19, стр. 8, пом. 2 \\ E-mail: earhortus@mail.ru
}

Проведена ревизия традиционной спецификации понятия «кредит», рассмотрен признак кредитной классификации «потребление/капитализация ссуженной стоимости». Обосновано критериальное деление видовых дефиниций экономической категории «кредит». Развиты научные представления о потребительском кредите.

Ключевые слова: кредит, ссуженная стоимость, потребительский кредит, персональный кредит, предпринимательский кредит, потребительское кредитование.

Непрерывное развитие финансово-экономического категориального аппарата экономической науки является отражением динамичности фактического развития структуры финансового инструментария реальной экономической жизни хозяйствующих субъектов. Кредит, выполняя свою контрольно-распределительную функцию, является наиважнейшим структурным элементом финансово-экономической системы государства. Экономическое воздействие и социально-политические экстерналии кредита способствуют повышению качества жизни населения и развитию предпринимательства посредством стимулирования деловой активности хозяйствующих субъектов.

Неотъемлемым стабилизатором современной рыночной экономики является кредитный механизм, как акселератор хозяйственной деятельности и фактор снятия противоречий спроса и предложения в координатах места и времени. Кредит является наиважнейшим структурным элементов всей совокупности финансовых продуктов, являясь формой одалживания денежных средств под проценты, непосредственно влияет на платежеспособный спрос населения, распределенный во времени [4]. Целевое намерение кредита заключается в авансировании воспроизводства/расширенного воспроизводства структуры денежных средств как домохозяйств, так и корпоративных субъектов.

Кредит, являясь драйвером расширения потребления и воспроизводства, обладает качествами активного фактора, выступает катализатором активности субъектов кредитования и детерминантой экстенсивного и интенсивного денежно-материального микро- и макроэкономического расширения. С этих позиций кредит следует рассматривать как ликвидную, торгуемую форму актива, формирующую настоящую денежно-материальную платформу или генерирующую будущие денежные поступления, базирующуюся на договорном денежном требовании кредитора к заемщику [3].

Экономическая наука традиционно раскрывает категорию «кредит» как экономические отношения по поводу движения ссудного капитала в целях авансирования производства/воспроизводства/расширенного воспроизводства путем денежной эмиссии/денежного перераспределения на условиях срочности, платности, возвратности [2;5].

Кредит как экономическая категория широко изучена, но акцент делается на пассивности данной категории. Сегодня имеется множество форм активизации кредита, но главным является способность кредита выполнять функции не только эластичного механизма перераспределения средств между субъектами (отток), но и механизма рефинансирования субъектов экономических отношений (приток).

Современные реалии неизбежно трансформируют понятие кредита, как формы движения стоимости (кредит-форма) в объектную плоскость дистинкции кредита как стоимости. Кредит, являясь объектом купли-продажи, сам является стоимостью, обнаруживая в себе атрибуты товара (цена, качество, спрос и предложение). Не являясь традиционным товаром, кредит обладает и специфической атрибутивностью. Цена кредита формируется под влиянием спроса и 
предложения, диктуется законами рынка, неизменно стремящегося к равновесию. В контексте социально-экономической значимости кредита в современном хозяйствовании, неизбежна тенденция к укреплению качества кредита, как важнейшего фактора способности кредита торговаться, участвовать в качестве самостоятельного инструмента в трансакциях, выходить на рынок капитала. В современной экономике кредит играет новую роль, становясь товаром, на который распространяются все законы товарооборота [3]. Таким образом, кредит является товарным механизмом перераспределения денежных средств посредством торговли ссуженной стоимостью.

Исследовательское сообщество на протяжении всей истории существования практики потребительского кредитования ведет дискуссии о сущности потребительского кредита как экономической категории. В современной экономической мысли отсутствуют четкие признаки, которые позволили бы отнести те или иные виды кредитно-финансовых услуг к категории «потребительский кредит». Определяющие разногласия наблюдаются при дифференциации всей группы потребительских кредитов от совокупного видового массива кредитов. Автор настоящего исследования относит к потребительскому кредиту любой розничный кредитный продукт, базирующийся на конечном потреблении ссуженной стоимости, погашение задолженности по которому происходит за счет регулярных непредпринимательских доходов (при условии соблюдения классических принципов кредитования: возвратности, срочности, платности).

В российской экономической доктрине узкая трактовка категории потребительский кредит определяет эту дефиницию как кредит на приобретение товаров, работ, услуг для целей личного, семейного и домашнего использования (преимущественно товаров мало длительного и средне длительного пользования) [2]. Автор видит принципиальным расширение трактовки понятия «потребительский кредит» и определении его базирования на идее не только индивидуального/персонального/личного характера использования заемных денежных средств, но и на концепции принципиального обособления источниковой базы погашения ссуженной стоимости при дифференциации кредитных продуктов.

На основании критерия доходного источни- ка погашения кредитной задолженности весь категориальный массив кредитов делится на две большие группы: потребительские (личные/персональные/индивидуальные) кредиты и предпринимательские (корпоративные/бизнес) кредиты с дальнейшей их подвидовой классификацией. Источником погашения предпринимательского кредита служат доходы от использования непосредственно ссуженной стоимости, ее капитализации. Источником погашения потребительского кредита служат доходы заемщика от текущей деятельности, не связанной с авансированием ссуженной стоимости.

Исходя из этого, дистинктивной особенностью потребительского кредитования является обмен ссуженной стоимости на товарно-материальный носитель без прямой капитализации ссуженной стоимости. Экономическое же содержание всей группы предпринимательских кредитов заключается в целевой установке субъектов корпоративного кредитования наращивания ссуженной стоимости и прямой ее капитализации.

С этих позиций предпринимательские кредиты носят прямой приростный эффект (ярко выраженный экстенсивный стратегический экономический эффект), потребительский же кредит носит принципиально отличный характер интенсивного улучшения текущего денежно-материального положения субъекта заимствования при условии совокупного макроэкономического катализирующего воздействия как потребительского, так и предпринимательского кредитов.

Таким образом, критерий «потребление/капитализация ссуженной стоимости» обеспечивает логическое сущностное обособление двух принципиально отличных видов кредита, «потребительского кредита» и «предпринимательского кредита», вне зависимости от формальной их имплементации. Критерий «потребление/ капитализация ссуженной стоимости» автоматически включает в себя два взаимоувязанных фактора-цель использования кредитных ресурсов и источник погашения ссуженных денежных средств, обоюдно характеризующих характер движения ссуженной стоимости.

Критерий «потребление/капитализация ссуженной стоимости» де-факто определяет направленность движения ссуженной стоимости путем видовой формализации кредита, сущностно дифференцируя всю потребительско- 
предпринимательскую совокупность кредитно-финансовых отношений.

При условии неизменности денежной модальности ссуженной стоимости и родовых характеристик (срочность, платность, возвратность), потребительский кредит принимает различные фактические формы, как традиционные (очный потребительский кредит на неотложные нужды, потребительский заем), так и производные (товарный кредит, кредитный карточный продукт).

Вся совокупность розничных кредитных продуктов объединяется некой агрегированной категорией «потребительский кредит», базирующейся на прерогативе непроизводственного (потребительского) характера использования ссуженной стоимости, отсутствия капитализации последней.

Институциональный фон персонального кредитования формирует широкие возможности инфраструктурного распределения возможностей потребительского кредитования через систему финансовых институтов (банки, микрофинансовые организации, ломбарды, кредитные кооперативы) и розничных торговых, сервисных сетей [1].

Потребительское кредитование занимает важное место в структуре розничного рефинансирования как механизм балансирования системы удовлетворения финансовых потребностей граждан. Персональный кредит является универсальным средством удовлетворения денежно-материальных потребностей населения, снимающим противоречие временных расхождений в покупательской платежеспособности и потребительской потребности физического лица.

Потребительский кредит, являясь объективно необходимым средством перераспределения материальных ресурсов в интересах развития общества в целом, воздействует на непрерывность процессов финансового воспроизводства домохозяйств. Использование потребительского кредита позволяет выравнивать планы покупательного поведения потребителя путем нивелирования возникших несовпадений моментов денежных доходов и расходов физического лица в координатах места и времени.

Институт потребительского кредитования является инструментом публичного субъектного перераспределения финансовых ресурсов, базируясь на общественном генезисе ссудного капитала. Основываясь на кредитном характере, часть эмитированной денежной массы, учитывая, что ссудный капитал является результатом государственной денежной эмиссии, трансформируется в потребительский кредит, становящийся фактором стимулирования потребительской активности.

Потребительский кредит является стабилизирующим элементом персонального рефинансирования, снимает противоречие разно расположенных во времени моментов способности и потребности удовлетворения различных целей потребления, позволяет без превентивного длительного накопления способствовать удовлетворению потребностей физических лиц посредством привлечения заемных источников финансирования. Потребительский кредит, с учетом характера потребностей граждан, отражает всю гамму и специфику стратификации потребления.

Институт потребительского кредитования является цивилизованным средством дополнительного финансирования платежеспособного спроса населения. Посредством персонального кредитования обеспечивается выравнивание потребительского поведения и покупательного планирования физического лица. Эффективно функционирующая система потребительского кредитования является неотъемлемой частью фундаментализации всей совокупности рыночных экономических отношений.

\section{Библиографический список}

1. Архипова Е.M. Банковское потребительское кредитование в России: проблемы и суждения/ Е.М. Архипова// Фундаментальные и прикладные исследования в области экономики и финансов: сборник научных статей IV международной научно-практической конференции. Часть 1. 7 декабря 2018 г., г. Орел. 2018. C.12-16.

2. Иваницкий В.П., Ковтун Р.С. Теоретические основы и экономическая сущность потребительского кредитования// Известия УрГЭУ.2008.№ 1(20). С.91. 
3. Клевцов B.В., Архипова Е.M. Развитие научных представлений о кредите и ипотечном кредитовании // Тверь: Вестник Тверского государственного университета. Серия: Экономика и управление. 2015. № 1-1. С. 100-107.

4. Лаврушин О.И. Базовые основы теории кредита и его использование в современной экономике//Journal of Economic Regulation (Вопросы регулирования экономики).2017.Том8, № 2.C.6-15.

5. Челноков В.А. Кредит: сущность, функции и роль// Деньги и кредит. 2012.№ 5.С.75.

Поступила в редакцию 31.12.2018 